\title{
From eLearning to Digital Transformation: A Framework and Implications for L\&D
}

\author{
http://dx.doi.org/10.3991/ijac.v9i2.6003 \\ Sabine Seufert \& Christoph Meier \\ University of St.Gallen, St.Gallen, Switzerland
}

\begin{abstract}
How can the learning function (L\&D) support learning and innovation at the level of an entire organization in times of digital transformation? The core challenges in this are twofold: 1) Competence clarification: What are relevant "digital competences" in terms of knowledge, skills and attitudes that employees need in order to cope with digital transformation? 2) Competence development: How to organize, design and support learning processes contributing to digital competences and digital transformation?

Building on a framework originating in the context of business engineering and applying it to corporate training and human resource development, we explicate what digital transformation implies for the L\&D function. As L\&D functions explore and exploit the options sketched out, they live digital transformation in a way that enables them to effectively and efficiently contribute to digital transformation at an organizational level.
\end{abstract}

Index Terms-Corporate L\&D, eLearning, digital competences, digital transformation, learning management.

\section{DigITAL TRANSFORMATION}

\section{A. Digital transformation as challenge and opportunity}

Digital transformation currently is one of the major challenges in all industries. It embraces the realignment of technologies and business models to more effectively engage customers at every touchpoint in the customer experience lifecycle. Therefore, successful digital transformation begins with an understanding of digital consumer behavior, preferences and choices. In a next step, major consumer-centric changes within the organization are required to address these needs. The implications are relevant for all industries. Organizations will need to continue existing services, while developing strategies to manage the shift in mix between analog and digital [1].

For that reason, organizations are challenged to consider the exploration of new business opportunities over and above currently existing ones. They have to establish a general development orientation and implement innovations while at the same time pursuing efficiency in utilizing and optimizing existing business opportunities. In consequence, there is pressure on organizations to engage in dynamic development. Hence, they need to enhance their continuous learning ability, an essential precondition for coping with change and successfully establishing innovations [1].

\section{B. Digital transformation in education and corporate learning}

Digital transformation is also discussed in the context of educational organizations: institutions at primary, sec- ondary and tertiary levels as well as providers (internal or external) of corporate training and human resource development services. In the corporate context, the topics discussed range from new formats for learning and development (e.g., MOOCs and nanodegrees, informal learning and performance support), platforms for learning and collaboration (e.g., cloud based services) as well as integrated processes (e.g., from knowledge maps via competency gap analyses to training needs aggregated at the company level) (see [2], [3], [4]). In addition, it is argued that digital transformation is not a matter of "bolting on" elements of social and mobile learning to existing services and programs but rather a matter of establishing changed cultures of learning and defining new business models for corporate L\&D [5]. This is particularly relevant if one accepts the premise that workplace learning first and foremost takes place in the (increasingly digital) workplace rather than in a segregated training area [6].

Looking at educational institutions more generally, digital transformation can be understood as affecting all major processes from educational marketing and application / participant / student management via program / course development and delivery all the way to assessment, certification and alumni management [7].

There are several implications of the above for corporate $L \& D$ :

1) L\&D units need to be able to 1) clarify competences required for successfully doing business in a digital economy (knowledge, skills and attitudes of both leaders and employees) and 2) effectively and efficiently develop these competences.

2) In order to achieve this, $L \& D$ needs to broaden its scope. It is not sufficient to provide formal training services. Above and beyond this, L\&D needs to facilitate and support non-traditional and informal learning activities throughout the organization [8].

3) Finally, L\&D needs to transform itself. L\&D cannot effectively support digital transformation of the entire organization if it does not "go digital" itself. It has to live and breathe digital life, explore the opportunities provided by digital transformation and become effective in providing learning services in a digital world.

\section{DIGITAL TRANSFORMATION IN L\&D: A FRAMEWORK}

Building on concepts derived from business engineering, Berghaus et al. have proposed a framework for digital transformation and business development [9, 10]. Their model comprises both a range of business engineering aspects and a maturity scale. According to them, digitally mature organizations, are characterized by the following: 
1) Customer experience - they provide products and services that are aligned with the digital lifestyle of customers.

2) Product innovation - they employ digital technologies in order to provide innovative products and services.

3) Strategy - they focus their strategy on exploiting the potential of digital technologies.

4) Organization - they provide digital competences internally in an effective and efficient manner.

5) Processes - they align all processes with digital structures and employ automatization wherever possible.

6) Collaboration - they employ digital technologies within the organization to support and enhance communication, collaboration and mobile working.

7) ICT - they employ IT infrastructures and information systems so as to enable new digital products, services, communication and transaction.

8) Culture - they are open to and command an understanding of digital technologies; relevant skills are deeply rooted in the organization.

9) Transformation - they manage digital transformation as a process at the top leadership level and they are guided by a clearly formulated roadmap.

Based on our understanding of educational management [11], we have adapted this framework for the realities of L\&D units as support functions within business organizations and will cover the following aspects in this contribution:

- $\quad$ Mission and vision for L\&D

- Strategy

- Customer experience

- Innovation and change process

- Product and service portfolio

- Processes

- Roles

- Communication and collaboration

- $\quad$ IT infrastructure.

An overview of the adapted framework for digital transformation of corporate L\&D is provided in Table II, below.

\section{DIGITAL TRANSFORMATION IN L\&D: EXPLICATION OF THE FRAMEWORK}

\section{A. Mission and vision}

L\&D units are service functions. Their mission, usually, is to support their organization's strategic goals. Currently, an important overarching goal for many organizations is to speed up organizational learning and innovation in times of digital transformation so as be as successful as possible in a digital economy. A possible vision for L\&D units (or an element in such a vision) is to be able to provide this support in an effective and efficient manner and thereby to firmly establish itself as a valued business partners not to be replaced by an external service provider [12].

\section{B. Strategy}

A strategy is the roadmap for achieving the mission and vision. In the context of digital transformation, relevant strategic initiatives for L\&D might focus on developing key digital competences as well as on the systematic exploration and exploitation of digital media for products and services. Exploration and exploitation of digital media

is discussed further below. For the moment, we will briefly look at relevant competences.

What are the competences required for digital transformation? A large number of frameworks and characterizations have been put forward, most of them based on skills development and the ability to use a specific set of tools and applications. Digital Competence can be defined as "the set of knowledge, skills, attitudes (thus including abilities, strategies, values and awareness) that are required when using ICT and digital media to perform tasks; solve problems; communicate; manage information; collaborate; create and share content; and build knowledge effectively, efficiently, appropriately, critically, creatively, autonomously, flexibly, ethically, reflectively for work, leisure, participation, learning, socializing, consuming, and empowerment." [13]. Table 1, below, provides the competence dimensions and examples of competences proposed by [14].

TABLE I.

COMPETENCE DIMENSIONS AND EXAMPLES OF COMPETENCES

1 Information

2 Communication

3 Content creation

4 Safety

5 Problem solving

Digital competences go beyond subject matter competences as the ability to use specific tools or applications in performing tasks. They also comprise critical thinking abilities, particularly with regard to contextualizing and evaluating information. And they also comprise social competences as these are relevant for matters such as understanding digital identities as well as communication and collaboration in a digital world [15].

Grounded in the discussion on digital literacy, [16] propose a framework for digital competence keyed to digital transformation and comprising three levels:

1) Digital competence as general skills and attitudes organized around key processes which may be mas- 
tered at different levels of expertise, varying from basic skills to more analytical competence.

2) Digital usage as the application of digital competence within specific professional or domain contexts.

3) Digital transformation as achieved when digital usage enables innovation and creativity and stimulates significant change at the individual or organizational level.

We will take up the idea of three levels of competences again towards the end of this contribution.

\section{Customer experience}

The 'customers' of L\&D include representatives of business functions as well as participants to courses and users of services (e.g., content curation services). In order to provide products and services that are appreciated and valued, L\&D needs to understand not only customer expectations but also customer experiences and journeys [17]. This is true for both basic phases in the customer journey: 1) becoming a customer of L\&D and 2) being a customer of L\&D. While there are many important touch points along the customer journey that are not related to digital transformation, more and more of them are: web pages or intranet pages with information on courses, learning resources and services; participant testimonials in communities and forums; online registration; welcome mail messages and welcome videos for participants; online learning platforms / LMSs with good (or not so good) usability on mobile devices; online learning materials; immersive learning environments in the form of serious digital games or online simulations; collaboration platforms for team assignments; etc.

\section{Innovation and change process}

In order to fulfil their mission with respect to digital transformation (see above), L\&D units have to provide learning opportunities that are 1) designed to systematically develop digital competences among employees and 2) aligned with expectations of already digitally minded employees. To achieve this, L\&D has to engage in innovation and change relating to new service formats (e.g. support for informal and social learning, see below), altered processes (e.g. increasing use of digital resources in the process of learning, see below) or new roles (e.g. the role of a learning content curator, see below). This requires L\&D to manage two processes in parallel [18]:

1) The innovation process, typically unfolding via the steps "invent" (often outside of L\&D), "innovate" (e.g. introducing an innovation such as a flipped classroom course design for a first time) and "roll out" (e.g. spreading and making flipped classroom course designs a common format).

2) The change process, typically unfolding via the steps "unfreeze" (e.g. confront internal trainers with challenges related to established training designs), "move" (e.g. point out advantages of flipped course designs and enable trainers to make these happen) and "stabilize" (e.g. support trainers in altered work practices so as to make flipped designs a routine affair).

\section{E. Product and service portfolio}

Developments in digital technologies (Web 2.0 and social media) have given rise to a heightened interest in informal learning and learning facilitated through social media [19]. These developments have led to numerous voices calling for a reinvention of corporate learning (e.g.
[20]). It has been argued that corporate learning may become superfluous in the future as web-savvy employees will solve knowledge and performance issues themselves rather than look for training services [21]. In order to evade this fate, corporate L\&D will need to broaden its scope and mission, providing not only professionally designed and managed formal learning opportunities, but also supporting informal learning in the workplace (see [11], [22], [23]).

Relevant additions to standard and extended training services (the latter including specifically designed transfer and performance support) are the following: curation services relating to learning contents as well as tools for personal learning and personal knowledge management (for the latter, refer to [24]); facilitation services relating to reflection and learning in the workplace (for example support for team leaders aiming at the transformation of selected team activities and meetings to learning situations); and, finally, enablement as well as support services for informal learning (for example in networks and communities).

Currently, much attention is devoted to supporting social and informal learning through digital media. However, digital transformation also provides much development potential when it comes to formal learning. We will look at this aspect in some more detail.

With regard to formal blended learning, several basic designs have emerged over the last 15 or so years. These comprise, among others, transfer oriented designs, projectbased models and flipped classroom models featuring either three or two distinct phases. Often, the assumption is that digital media can be usefully employed only or primarily in online phases but not so much during on site phases.

However, digital transformation in working and learning environments makes this distinction between on line and on site blurry. Increasingly, workers and learners are always online and always have mobile computing devices at their hand - regardless of whether they are in the office, on the shop floor, commuting, at home or in a physical training room. In consequence, which learning activities take place at a physical learning facility and which at other locations becomes less relevant. Key to success in learning is the focused pursuit of learning outcomes through the orchestration of activities, tools and media.

Designs for formal learning and training may comprise the following basic elements [25]:

- orienting learners / participants to the program and soliciting ambitions and / or concerns;

- determining prior knowledge;

- motivating and linking to prior knowledge,

- presentations;

- dialogic development;

- individual or team assignments aiming at either developing or applying solutions to problems;

- $\quad$ sharing and discussing solutions;

- assignments aimed at practicing and routinizing;

- determining progress or status in preparation for a final assessment or certification;

- documenting and / or reflecting on learning. 
TABLE II. DIGITAL TRANSFORMATION FRAMEWORK FOR L $\& D$

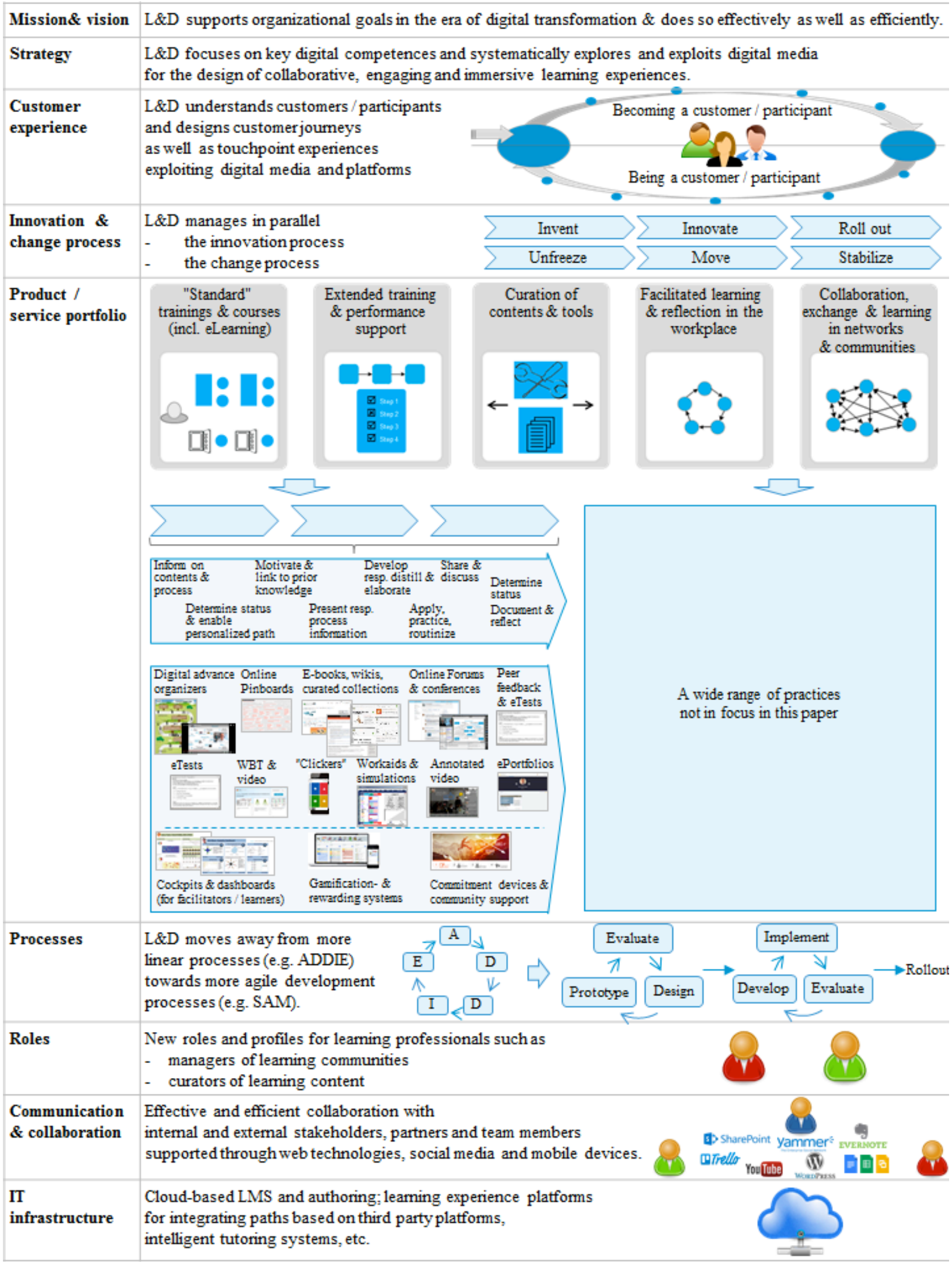


Alongside these activities, both teachers / facilitators and participants alike need to plan, monitor, and motivate learning activities: their own activities (learners / participants) and the activities of participants in a given course or program (teachers / facilitators).

Each and every activity mentioned above (and others not mentioned) can be supported through the use of digital media. For example:

- attractive advanced organizers can be created (and easily shared) on the basis of web services for visuals or infographics;

- virtual pin boards can help obtain (anonymized) voices (hopes / concerns etc.) from participants at an early stage in the learning journey;

- classroom response systems ("clickers") can help determine (in an anonymous manner) where participants stand with regard to key concepts / knowledge / attitudes throughout a course - from the beginning right through to the end; trainers / facilitators can employ this information so as to better connect to prior knowledge or to conduct brief classroom assessments (which in turn may indicate required adjustments to the planned program);

- web based trainings (WBT), eBooks, videos and curated collections can provide materials for selfstudy as well as team assignments - both outside of as well as during on-site sessions;

- student work can be documented in and shared via personal digital notebooks, personal weblogs or study team wikis;

- course weblogs and course wikis can be employed to document work results generated during a facilitated classroom session;

- digital worksheets and performance aids allow for easy adaptation and integration in the personal work environment later on;

- video recordings of role plays, presentations or other work activities such as handling of machinery can be annotated, commented on and discussed via services for social video learning;

- results of individual work and teamwork can be discussed in between on-site sessions via online forums and community platforms;

- virtual classrooms sessions can be employed for the same purpose and may also be used to integrate brief contributions from off-site experts during on-site sessions;

- documentation of and reflection on learning and personal development - along with sharing and peer feedback processes - can be supported through personal weblogs and ePortfolio systems;

- cockpits and dashboards can support both teachers / facilitators and participants in monitoring activities and in keeping up to date on requirements or submissions [26];

- gamification and rewarding systems can support student motivation and participation in course activities - even though there is a debate on how effective extrinsic motivating factors such as points or leaderboards are in the long run [27];

- commitment devices such as personally configured reminders and community support services (e.g. www.stikk.com) can assist participants in specifying and attaining personal goals; recent research indicates that the use of such systems contributes to study success [28].

This is not to suggest that employing the tools and media mentioned is an end in and of itself. Innovation on a technical level through the use of new media and tools does not necessarily lead to didactical innovation or quality improvement [29]. Employing digital media and tools needs to be guided by their benefits and affordances relative to the goals that are pursued and their contribution to a "strong" learning environment [30].

\section{F. Processes}

The portfolio of services for formal and informal learning mentioned above is realized via a range of different processes. With regard to formal learning, standards have been established. These involve models such as ADDIE (Analysis, Design, Development, Implementation, and Evaluation) or Gagné's nine steps of instruction and derivatives of these (see the discussion above and [25]). When it comes to the management of projects in corporate L\&D, the ADDIE model is challenged by models such as SAM [31], which are inspired by prototyping approaches and design thinking. Agile approaches to managing projects in L\&D are relevant not only for the development of eLearning resources such as WBT or platforms employed in training but for other projects as well. Tools for digital collaboration (see section $\mathrm{H}$, below) both within and across organizational boundaries support this move towards more agile procedures.

\section{G. Roles}

The extension of the service portfolio (see section E, above) gives rise to new roles and profiles for learning professionals. Examples are curators of learning content, facilitators supporting reflection and change in work teams or managers of learning communities. Learning content curators, for example, survey the landscape of easily available learning resources. Examples are open courses offered by various MOOC providers (and aggregated by specialized websites such as www.classcentral.com/), Open Educational Resources (OER) made available through specific portals (e.g. www.oercommons.org or www.merlot.org) or providers of large libraries of video resources for learning, both commercial (e.g. www.lynda.com) and non-commercial (e.g. khanacademy.org/). Key tasks and challenges include the identification of relevant resources, the assessment of their fit with internal requirements (e.g. level, length, workload, pacing, etc.) and making these resources accessible for internal users. The latter aspect may be achieved, for example, via manually created overview pages, via dedicated curation services (e.g. scoop.it) or via technical integrations with existing platforms.

\section{H. Communication \& collaboration}

In order to provide the above mentioned products and services in both formal and informal learning, L\&D professionals need to collaborate efficiently and effectively with both internal and external partners: business partners; concept developers; designers of courses and media; trainers and facilitators; IT experts, etc. In the context of increasingly digital workspaces and the need for resource efficiency, L\&D needs to be fluent in a wide range of technologies for supporting communication, collaboration and (informal) learning.

\section{IT infrastructure}

For a long time, IT infrastructure for learning (both "traditional", online and blended) has been synonymous with learning management systems (LMS) - which have been pronounced dead as often as they have been called indispensable [32]. Recent developments with regard to IT 
infrastructures for learning include moves toward cloud based LMS services and cloud based authoring services. In addition, new types of systems are becoming available. These include intelligent tutoring systems [33], mobile apps as access points to learning and performance support or learning experience platforms that support the integration of learning contents that is distributed on different external platforms and marketplaces [3].

Learning professionals often perceive internal IT services as taking a hard line with $L \& D$, blocking efforts to explore and exploit innovative web services in the realm of learning. This is particularly true in security conscious industries such as banking. In order to support digital transformation in the organization, L\&D needs to build alliances with other units and to jointly engage IT services in discussion on what is desirable, what is necessary and how the infrastructures required can be made available.

\section{MOVING FORWARD}

We started out on this paper by asking how corporate L\&D functions can contribute to enhancing an organization's learning and innovation ability in times of digital transformation. A framework for digital competences provides L\&D functions with a starting point. However, digital transformation requires not only general skills and attitudes. These skills and attitudes have to be applied and used in the specific functions and professional domains that constitute the organization. Digital transformation emerges when usage enables innovation and creativity that then leads to significant change - at the individual or organizational level.

As L\&D units and L\&D professionals pursue "going digital" in their own domain and operations, they experience digital transformation firsthand in a way that enables them to effectively support digital transformation at an organizational level. The framework we have been developing in this contribution points out what learning professionals need to work on in the pursuit of this transformation.

\section{REFERENCES}

[1] D. Schuchmann, D., and S. Seufert, "Corporate Learning in Times of Digital Transformation: A Conceptual Framework and Service Portfolio for the Learning Function in Banking Organisations.", International Journal of Advanced Corporate Learning (iJAC), vol. 8, pp. 31-39, 2015. http://dx.doi.org/10.3991/ijac.v8i1.4440

[2] J. Bersin, D. Agarwal, B. Pelster, and J. Schwartz (eds.), „Global Human Capital Trends 2015. Leading in the new world of work”. Deloitte University Press, 2015, http://d27n20517rookf.cloud front.net/wp-content/uploads/2015/08/DUP_GlobalHumanCapital Trends2015.pdf.

[3] J. Bersin, "HR technology for 2016: 10 big disruptions on the horizon". Perspective, Bersin by Deloitte. https://www2.deloitte.com/content/dam/Deloitte/pa/Documents/hu man-capital/201512 10disruptions horizon.pdf.

[4] J. Wildi-Yune, „3.27: Digitales Lernen in Unternehmen erfolgreich einsetzen", in Handbuch E-Learning. Expertenwissen aus Wissenschaft und Praxis, 61. Ergänzungslieferung, K. Wilbers, Ed. Cologne: Wolters Kluwer / Deutscher Wirtschaftsdienst, January 2016.

[5] J. Hart, Digital transformation of workplace learning; going beyond "bolt-on", Weblog post, June 9 2015, http://www.c4lpt.co.uk/blog/2015/06/09/digitaltransformation-of-workplace-learning-going-beyond-bolton/.

[6] J. Hart, "The 2 views of workplace learning: L\&D and Employee" Weblog post, February $11 \quad 2016$, http://www.c4lpt.co.uk/blog/2016/02/11/the-2-views-ofworkplace-learning-ld-and-employee/.

[7] M. Kerres, ,2.22: E-Learning vs. Digitalisierung der Bildung? Neues Label oder neues Paradigma?" in Handbuch E-Learning. Expertenwissen aus Wissenschaft und Praxis, 61. Ergänzungslieferung, K. Wilbers, Ed. Cologne: Wolters Kluwer / Deutscher Wirtschaftsdienst, January 2016.

[8] J. Hart, (2014). Informal learning takes off (eLearning Guild Research). Santa Rosa, CA: eLearning Guild.

[9] S. Berghaus, A. Back, and B. Kaltenrieder, „Digital Transformation Report 2015“, Report, Institut für Wirtschaftsinformatik, Universität St.Gallen.

[10] A. Back and S. Berghaus, Digital Maturity Model. Presentation slides. No date. https://crosswalk.ch/media/25590/digital matu rity_model_download.pdf

[11] S. Seufert, Bildungsmanagement: Einführung für Studium und Praxis, Stuttgart: Schäffer-Poeschel, 2013.

[12] D. Roberts, "Top 5 tips for outsourcing your learning and development", Weblog post, August 17 2015, http://www.innovationmanagement.se/inside/iframe/single.php?ci $\mathrm{d}=\& \mathrm{p}=47361$.

[13] A. Ferrari, Digital competence in practice: An analysis of frameworks, EUR 25351, JRC Technical Reports, Luxembourg: Joint Research Centre, Institute for Prospective Technological Studies, 2012, http://ftp.jrc.es/EURdoc/JRC68116.pdf.

[14] A. Ferrari, DIGCOMP: a framework for developing and understanding digital competence in Europe, EUR 26035, JRC Scientific and Policy Reports, Luxembourg: Joint Research Centre, Institute for Prospective Technological Studies, 2013, http://ftp.jrc.es/EURdoc/JRC83167.pdf.

[15] T. Newman, Digital Literacy literature review: from terminology to action, Presentation slides, http://de.slideshare.net/TabethaNew man/digital-literacy-literature-review-from-terminology-to-action.

[16] A. Martin and J. Grudziecki, "DigEuLit: Concepts and tools for digital literacy development. Innovation in Teaching and Learning", Information and Computer Sciences, vol. 5, pp. 1-19, 2006.

[17] J. Trischler, and D.R. Scott, "Designing Public Services: The usefulness of three service design methods for identifying user experiences", Public Management Review, vol. 18, pp. 718-739, 2016. http://dx.doi.org/10.1080/14719037.2015.1028017

[18] S. Seufert and C. Meier, „E-Learning in Organisationen. Nachhaltige Einführung von Bildungsinnovationen“, in L3T Lehrbuch für Lernen und Lehren mit Technologien (2nd edition), S. Schön and M. Ebner, Eds. 2013, www.13t.eu.

[19] J. Cross, Informal learning: Rediscovering the natural pathways that inspire innovation and performance. San Francisco, CA: Pfeiffer, 2007.

[20] M. Conner, D. Pontrefact, and K. Brown, Learning Nouveau Revolutionize corporate learning: beyond formal, informal, mobile, social dichotomies, Report, May 2013, http://marciaconner.com/learning-nouveau/.

[21] J. Hart, The workplace learning revolution. Free mini e-Book, Version 2, May 2013, www.c4lpt.co.uk. http://www.c4lpt.co.uk/ blog/2013/05/07/the-workplace-learning-revolution-free-mini-ebook/.

[22] Hart, J. (2015, Juni 9). Digital transformation of workplace learning; going beyond „bolt-on“ [Weblog]. Abgerufen von http://www.c4lpt.co.uk/blog/2015/06/09/digital-transformation-ofworkplace-learning-going-beyond-bolt-on/

[23] P. Ghislandi, M.G. Ierardi, T. Leo, and L. Spalazzi, "Guest editorial: Innovative technologies for the seamless integration of formal and informal learning”, Educational Technology \& Society, vol. 16, pp. 1-3, 2013.

[24] D. Pauleen and G. Gorman, Personal Knowledge Management: Individual, Organizational and Social Perspectives, Ed. Farnham: Gower Pub Co., 2011.

[25] D. Euler and A. Hahn, Wirtschaftsdidaktik, 3rd edition. Bern: Haupt, 2014, pp. 317.

[26] G. Siemens, D, Gasevic, C. Haythornthwaite, S. Dawson, S.B. Shum, R. Ferguson, ... R.S.J. Baker, Open Learning Analytics: an integrated \& modularized platform, 2011, http://solaresearch.org/ OpenLearningAnalytics.pdf. 
[27] K. Kapp, The Gamification of Learning and Instruction: Gamebased Methods and Strategies for Training and Education. San Francisco, CA: Pfeiffer, 2012.

[28] R.W. Patterson, Can behavioral tools improve online student outcomes? Experimental evidence from a massive open online course (Report), Cornell University, Department of Policy Analysis and Management, 2015, https://www.ilr.cornell.edu/sites/ ilr.cornell.edu/files/cheri wp165 0.pdf.

[29] S. Seufert, Innovationsorientiertes Bildungsmanagement. Hochschulentwicklung durch Sicherung der Nachhaltigkeit von eLearning. Wiesbaden: VS Verlag für Sozialwissenschaften, 2008, p. 192.

[30] J.D. Bransford, A.L. Brown, and R.R. Cocking, How people learn: Brain, mind, experience, and school. Expanded edition, Ed. Washington, USA: National Academy Press, 2000.

[31] M.W. Allen, Leaving Addie for SAM: An Agile Model for Developing the Best Learning Experiences. ASTD Press, 2012.

[32] D. Clark, D, "The LMS is dead, long live the LMS! (10 pros \& 10 cons)“, Donald Clark Plan B, Weblog post, March 5 2016, http://donaldclarkplanb.blogspot.ch/2016/03/the-lms-is-dead-longlive-lms-10-pros.html.
[33] M. M. Bagheri, "Intelligent and adaptive tutoring systems: How to integrate learners", International Journal of Education, 7(2), 2015.

\section{AUTHORS}

S. Seufert, Professor for Business Education and Educational Management at the University of St. Gallen, Director of the Institute of Business Education and Educational Management at the University of St. Gallen, Dufourstrasse 40a, 9000 St. Gallen, Switzerland (e-mail: sabine.seufert@unisg.ch).

C. Meier, Dr. rer.soc., Trainer and consultant at swiss centre for innovations in learning (scil), Institute for Business Education and Educational Management at the University of St. Gallen, Dufourstrasse 40a, 9000 St. Gallen, Switzerland (e-mail: christoph.meier@unisg.ch.).

This article is an extended and modified version of a paper presented at the International Conference on E-learning in the Workplace 2016 (ICELW 2016), held in June 2016, at Columbia University in New York, NY, USA. Submitted March 20, 2016. Published as resubmitted by the authors May 12, 2016. 